\title{
Dentists' Leadership-Related Educational Experiences, Attitudes, and Past and Current Behavior
}

\author{
L. Susan Taichman, R.D.H., M.S., M.P.H., Ph.D.; Russell S. Taichman, D.M.D., D.M.Sc.; \\ Marita R. Inglehart, Dr. phil. habil.
}

Abstract: The purpose of this study was to assess practicing dentists' perceptions of their leadership-related educational experiences during predoctoral education and after graduation, to investigate if these perceptions differed as a function of the respondents' graduation year and gender, and to explore the relationships between educational experiences and the respondents' understanding/perceptions of leadership, leadership-related attitudes, self-perceived effectiveness, and past and current leadership-related behavior. Of the 3,000 general dentist members of the American Dental Association who were invited to participate, 593 returned the survey for a response rate of 20 percent. Between 37 and 65 percent of the respondents indicated that their predoctoral dental education had not prepared them well on a series of factors related to being leaders in their practice, community, state, or at the national level. However, 33 to 77 percent of these dentists responded that educational experiences after graduation prepared them well for different types of leadership activities. Overall, respondents rated their predoctoral experiences significantly less positively than their experiences after graduation for each content area. The more recently the respondents had graduated, the higher they rated their leadership-related educational experiences. The better their educational experiences, the more important the respondents evaluated leadership activities in their practice, organized dentistry, and research/teaching, the more important they assessed leadership to be, and the more effective they evaluated themselves to be as leaders. The perceived quality of the respondents' predoctoral education was not correlated with their past and current leadership activities. The results of this study may suggest that improving leadership training during predoctoral education could positively affect future dentists' attitudes about leadership and ratings of their own effectiveness as leaders.

Dr. L. Susan Taichman is Assistant Professor and Research Scientist, Department of Periodontics and Oral Medicine, School of Dentistry, University of Michigan; Dr. Russell S. Taichman is Major M. Ash Collegiate Professor of Dentistry, Department of Periodontics and Oral Medicine, School of Dentistry, University of Michigan; and Dr. Inglehart is Professor of Dentistry, Department of Periodontics and Oral Medicine, School of Dentistry, and Adjunct Professor, Department of Psychology, College of Literature, Science, and Arts, University of Michigan. Direct correspondence and requests for reprints to Dr. Marita R. Inglehart, Department of Periodontics and Oral Medicine, School of Dentistry, University of Michigan, 1011 N. University Ave., Ann Arbor, MI 48109-1078; 734-763-8073; mri@umich.edu.

Keywords: dentists, leadership, community engagement, leadership training, dental education

Submitted for publication 9/30/13; accepted 11/25/13

$\mathrm{T}$ loday's health care system is comprised of heterogeneous groups of practitioners who provide complex care to increasingly diverse groups of patients. ${ }^{1}$ At the same time, the demands placed on health care providers continue to grow in response to patient expectations, legislative changes (e.g., the Affordable Care Act), and regulations including insurance coverage and occupational safety. ${ }^{2}$ Dentists, dental hygienists, and other health care providers are increasingly challenged to provide the best possible care to patients with complex treatment needs. ${ }^{3}$ Additionally, dentists are called upon to manage efficient small businesses and complex staffing issues while planning for a future that will continue to change at an accelerated pace. For all these reasons, it is crucial for dental clinicians, educators, researchers, and policymakers to develop strong leadership skills. ${ }^{4,5}$

In spite of these needs, Taichman et al. reported in 2009 that one-third of U.S. dental schools did not provide leadership training in their predoctoral curricula. ${ }^{6}$ The majority of those institutions that did include leadership education reported that the content was mainly in practice management courses that focused on leadership in the dental team. While Victoroff et al. reported in 2008 that the majority of students in their dental school were interested in leadership development during their predoctoral 
education, ${ }^{7}$ Kalendrian et al. pointed out that leadership coursework and experiences were still not part of mainstream dental curricula in $2010 .{ }^{8}$

Indeed, surveys of U.S. dental school seniors have found over the years that the majority felt their dental education had not prepared them well in the area of practice management. ${ }^{9-11}$ While such skills may be acquired as graduates enter the workforce, ${ }^{12}$ it is nevertheless important that dental schools strive to address their graduates' needs in this area. ${ }^{13}$ In addition, predoctoral education concerning dentists' participation in the health policy process has been largely lacking in the past, leaving the majority of new dentists unlikely to be prepared to become leaders in their communities and at the state and national levels. ${ }^{14}$

As dental education moves toward addressing these needs, a better understanding of the context is needed since many questions remain unanswered. It is interesting to reflect on whether female dentists differ in their perceptions of leadership-related educational experiences from their male colleagues, especially with the increasing percentage of female dentists. ${ }^{15,16}$ While dentists' gender has been found to be a significant determinant of their practice patterns, ${ }^{17,18}$ no differences have been identified in male and female postdoctoral residents' educational experiences in clinical practice, external rotations, or didactic courses. ${ }^{19,20}$

More generally, although previous research has explored which types of activities dental students consider to be indicators of leadership, the results are mixed. One study found that nearly all dental students in one school rated having a leadership role in their dental practice as an essential indicator of leadership, and about three-fourths perceived involvement in community activities as indicators of leadership. ${ }^{7}$ However, participating in organized dentistry and academic leadership were seen by far fewer of these students as leadership-related activities. A report of a leadership program at another dental school suggested that leadership was defined in a variety of ways and these views might be dependent on the institutional setting in which students are educated. ${ }^{13}$ For example, if dental schools offer community-based education or education about global oral health, ${ }^{21-25}$ these experiences may influence students' perceptions of the types of activities related to leadership. Similarly, educational efforts that engage students in health policymaking at the local and state levels ${ }^{14}$ or help postdoctoral residents develop core leadership skills $^{26}$ can be expected to focus the participants' attention in those ways. In medical education, research on the outcomes of leadership programs in community service showed an increase in students' sense of self-efficacy concerning their leadership skills in that area. ${ }^{27}$

In addition to continuing research with dental students, seeking the perceptions of practicing dentists regarding leadership skills and practices can be helpful in determining educational needs. However, no research so far has explored whether the quality of leadership-related dental education is related to dentists' sense of efficacy as leaders once they are in practice. To contribute to our understanding of the needs for leadership education in dental school, the objectives of this study were therefore as follows: 1) to assess dentists' perceptions of their leadershiprelated educational experiences during predoctoral education and after graduation (Aim 1);2) to investigate if these perceptions differed as a function of the respondents' graduation year or gender (Aim 2); and 3) to explore the relationships between educational experiences and the respondents' perceptions of which types of activities are indicators of leadership, their leadership-related values/attitudes, their self-perceived effectiveness as leaders, and their past and current leadership-related behavior (Aim 3).

\section{Methods}

This study was approved by the Institutional Review Board for the Behavioral and Health Sciences at the University of Michigan. Data were collected from a national sample of general dentists. Mailing addresses were obtained from the American Dental Association (ADA), and surveys were mailed to 3,000 ADA members.

The survey consisted of four parts. Part 1 assessed the respondents' demographic, education, and practice characteristics. Part 2 focused on how the respondents would define leadership in dentistry and asked for their level of agreement (on a scale from $1=$ disagree strongly to $5=$ agree strongly) with twenty questions concerning potential indicators of dental leadership. Part 3 asked respondents to indicate on a scale from $1=$ not at all to $5=$ very important how important six leadership-related aspects of dentistry were to them and to rate on a scale from $1=$ not at all effective to $5=$ very effective how effective they perceived themselves to be as leaders in their own practice and in their profession. The final section consisted of open-ended questions that inquired about 
the respondents' past and current leadership activities and experiences.

This survey was pilot-tested with seventeen part-time faculty members at the University of Michigan School of Dentistry. These participants were mostly male $(\mathrm{N}=16)$ and from European American backgrounds $(\mathrm{N}=12)$; they ranged in age from twenty-eight to seventy-eight years. The pilot data showed that some minor stylistic changes were needed to clarify some questions. However, the overall content of the survey was not changed.

After the survey data were collected, the responses to the educational questions, the items concerning the indicators of leadership, and the importance ratings were factor-analyzed to identify whether indices could be constructed (extraction method: principal component; rotation method: Varimax rotation). The factor analysis of the educational items showed that all predoctoral items loaded on a first factor, while three of the items after graduation loaded on a second factor related to leadership in the dental practice and three items on a third factor that can be described as experiences after graduation related to organizational leadership. Three indices were therefore computed by averaging the responses to the items loading on each factor. Cronbach alpha coefficients showed that these scales had good interrater reliability.

The factor analysis of the twenty items concerning various activities being leadership indicators resulted in four factors related to personal recognition (five items), practice-related considerations (four items), organized dentistry (seven items), and research and teaching (four items). One index for each of these four groups of items was constructed by averaging the responses to the items loading on each respective factor. The inter-item consistency of these four subscales was good. The factor analysis of the answers to the importance questions showed that the six items concerning the importance of various aspects of leadership loaded on one factor. An index was therefore constructed by averaging the responses to these items, and the inter-item consistency for the importance subscale was good as well.

The data were analyzed with SPSS (Version 19). Descriptive statistics such as frequencies, percentages, and means were computed to provide an overview of the responses. Pearson correlation coefficients were computed to determine the relationships between the educational items/indices and the graduation year, leadership, importance, and effectiveness indicators/indices. Kendall tau coefficients were computed to determine the relationship between educational experiences and gender. A p-value of $<0.05$ was considered statistically significant.

\section{Results}

Of the 3,000 dentists invited to participate in the study, 593 returned the survey to the investigators (response rate: 20 percent). Most of the respondents were male (77 percent) and from European American backgrounds ( 85 percent; with 9 percent Asian American, 3 percent Hispanic, and 2 percent African American). The respondents ranged in age from twenty-seven to ninety-seven years (average age $50.71 ; \mathrm{SD}=10.754$ ) and had graduated between 1964 and 2010 from fifty-four U.S. dental schools and sixteen dental schools outside the United States. In addition to their dental degree, some respondents had a degree in postdoctoral general dentistry (1 percent in Advanced Education in General Dentistry [AEGD] and 4 percent in a General Practice Residency [GPR]) or a master's degree (8 percent).

The first aim assessed how well the respondents perceived themselves to be prepared for leadership by their predoctoral education and by their educational experiences after graduation. Table 1 provides an overview of the responses. The responses concerning predoctoral education were rather negative. For example, 65 percent of the respondents disagreed that they had been well prepared by their predoctoral education to run an effective practice. The most positive response was related to how well they were prepared to interact and consult with colleagues in other practices. The responses concerning leadershiprelated educational experiences after graduation were more positive. A total of 71 percent of the respondents agreed or strongly agreed that such experiences prepared them well to run an effective practice, and 77 percent answered that those experiences helped them to be a leader in their practice. The responses concerning how educational experiences after graduation had prepared them for organizational leadership tasks were also more positive. Overall, the predoctoral experiences were significantly less positive than the experiences after graduation for each content area (Figure 1).

Aim 2 explored whether the respondents' perceptions of educational experiences were related to their graduation year or gender. The more recently the dentists had graduated, the more positively they described their leadership-related predoctoral educa- 
Table 1. Respondents' perceptions of leadership preparation provided by their predoctoral educational experiences and their educational experiences after graduation

\begin{tabular}{|c|c|c|c|c|c|c|}
\hline & $\begin{array}{c}1 \\
\text { Disagree } \\
\text { Strongly }\end{array}$ & $\begin{array}{c}2 \\
\text { Disagree }\end{array}$ & $\begin{array}{c}3 \\
\text { Neutral }\end{array}$ & $\begin{array}{c}4 \\
\text { Agree }\end{array}$ & $\begin{array}{c}5 \\
\text { Agree } \\
\text { Strongly }\end{array}$ & $\begin{array}{l}\text { Mean/SD } \\
\mathrm{N}=593\end{array}$ \\
\hline \multicolumn{7}{|l|}{ My predoctoral dental education prepared me well to: } \\
\hline run an effective practice. & $30 \%$ & $35 \%$ & $22 \%$ & $9 \%$ & $3 \%$ & $\begin{array}{l}2.19 / \\
1.06\end{array}$ \\
\hline interact and consult with colleagues in other practices. & $11 \%$ & $26 \%$ & $32 \%$ & $25 \%$ & $6 \%$ & $\begin{array}{l}2.88 / \\
1.09\end{array}$ \\
\hline be a leader in my practice setting. & $16 \%$ & $29 \%$ & $30 \%$ & $20 \%$ & $4 \%$ & $\begin{array}{l}2.67 / \\
1.10\end{array}$ \\
\hline be a leader in my community. & $17 \%$ & $31 \%$ & $31 \%$ & $17 \%$ & $3 \%$ & $\begin{array}{l}2.57 / \\
1.05\end{array}$ \\
\hline be a leader in my state. & $22 \%$ & $33 \%$ & $31 \%$ & $11 \%$ & $2 \%$ & $\begin{array}{l}2.36 / \\
-0.99\end{array}$ \\
\hline be a leader at the national level. & $27 \%$ & $32 \%$ & $29 \%$ & $9 \%$ & $2 \%$ & $\begin{array}{l}2.28 / \\
1.03\end{array}$ \\
\hline Index "Predoctoral education" (Cronbach $\alpha=0.907$ ) & & & & & & $\begin{array}{l}2.49 / \\
0.87\end{array}$ \\
\hline \multicolumn{7}{|l|}{ My experiences after dental school prepared me well to: } \\
\hline run an effective practice. & $4 \%$ & $7 \%$ & $18 \%$ & $45 \%$ & $26 \%$ & $\begin{array}{l}3.81 / \\
1.04\end{array}$ \\
\hline interact and consult with colleagues in other practices. & $2 \%$ & $3 \%$ & $16 \%$ & $47 \%$ & $30 \%$ & $\begin{array}{l}4.02 / \\
0.87\end{array}$ \\
\hline be a leader in my practice setting. & $2 \%$ & $5 \%$ & $16 \%$ & $47 \%$ & $30 \%$ & $\begin{array}{l}3.98 / \\
0.90\end{array}$ \\
\hline $\begin{array}{l}\text { Index "Experiences after graduation: leadership in } \\
\text { practice" (Cronbach } \alpha=0.853)\end{array}$ & & & & & & $\begin{array}{l}3.93 / \\
0.83\end{array}$ \\
\hline be a leader in my community. & $3 \%$ & $9 \%$ & $28 \%$ & $39 \%$ & $20 \%$ & $\begin{array}{l}3.63 / \\
0.99\end{array}$ \\
\hline be a leader in my state. & $7 \%$ & $17 \%$ & $36 \%$ & $27 \%$ & $12 \%$ & $\begin{array}{l}3.20 / \\
1.09\end{array}$ \\
\hline be a leader at the national level. & $13 \%$ & $19 \%$ & $35 \%$ & $22 \%$ & $11 \%$ & $\begin{array}{l}3.01 / \\
1.17\end{array}$ \\
\hline $\begin{array}{l}\text { Index "Experiences after graduation: organizational } \\
\text { leadership" (Cronbach } \alpha=0.897)\end{array}$ & & & & & & $\begin{array}{l}3.28 / \\
0.99\end{array}$ \\
\hline
\end{tabular}

Note: Percentages may not total 100 percent due to rounding.

tion (Table 2). However, no significant correlations were found between leadership-related educational experiences after graduation and graduation year. Concerning the relationship between the respondents' gender and educational experiences, women were more likely than men to report some positive predoctoral experiences and to report more positive experiences after graduation.

Aim 3 explored the relationships between perceived leadership-related educational experiences and the respondents' a) understanding/perceptions of which types of activities are indicators of leadership, b) leadership-related values/attitudes, c) self- perceived effectiveness as leaders, and d) past and current leadership-related behavior. Concerning the first factor of interest, the more positive the respondents perceived their predoctoral education to have been, the higher they rated the degree to which these twenty aspects were related to leadership (Table 3). The perceived quality of their leadership-related education after dental school was also related to the degree to which all but one group of items were interpreted as leadership indicators. The exception was that no significant relationship was found between the quality of practice-related educational experiences after dental school and how the respondents 


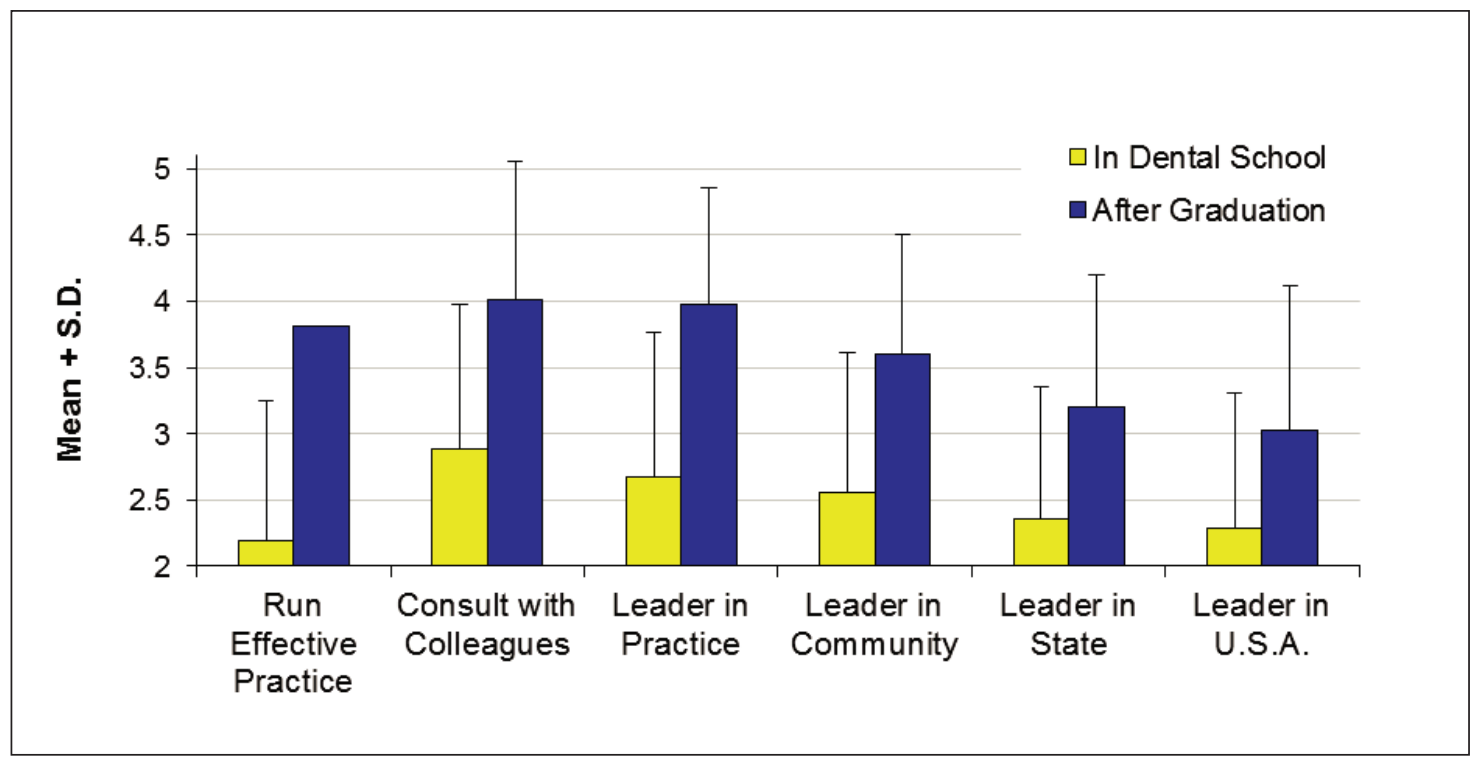

Figure 1. Respondents' perceptions of the quality of their educational experience to prepare them for specific leadership tasks, compared for predoctoral education versus after graduation

Note: Respondents rated quality of educational experiences on a five-point scale from $1=$ worst educational experience to $5=$ best educational experience.

Table 2. Correlations between respondents' year of graduation and leadership-related educational experiences during predoctoral education and after dental school

\begin{tabular}{lcc} 
& Graduation Year & Gender \\
\hline $\begin{array}{l}\text { My predoctoral dental education prepared me well to: } \\
\text { run an effective practice. }\end{array}$ & 0.025 & 0.10 \\
interact and consult with colleagues in other practices. & $0.19^{* * *}$ & $0.16^{* * *}$ \\
be a leader in my practice setting. & $0.26^{* * *}$ & 0.12 \\
be a leader in my community. & $0.21^{* * *}$ & $0.23^{* * *}$ \\
be a leader in my state. & $0.15^{* * *}$ & $0.20^{* * *}$ \\
be a leader at the national level. & $0.20^{* * *}$ & $0.22^{* * *}$ \\
$\quad$ Index "Predoctoral education" (Cronbach $\alpha=0.907)^{\dagger}$ & $0.13^{* * *}$ \\
My experiences after dental school prepared me well to: & 0.07 & 0.07 \\
run an effective practice. & 0.06 & 0.07 \\
interact and consult with colleagues in other practices. & 0.07 \\
be a leader in my practice setting. & 0.05 & 0.10 \\
$\quad$ Index "Experiences after graduation: leadership in practice" (Cronbach $\alpha=0.853)^{\dagger}$ & 0.06 \\
be a leader in my community. & 0.01 & 0.09 \\
be a leader in my state. & 0.02 & 0.11 \\
be a leader at the national level. & 0.03 & $0.13^{* *}$
\end{tabular}

Note: Response options ranged from $1=$ disagree strongly to $5=$ agree strongly (=best level of education). Pearson correlation coefficients were computed to determine the relationships between graduation year (column 1) and responses to the educational items. Contingency coefficients were computed to determine the relationships between gender (column 2), which was coded as male $=1$ and female $=2$, and responses to the educational items. Kendall's tau b coefficients were computed to determine the relationship between gender and the three indices.

${ }^{*} p \leq 0.05 ;{ }^{* *} p \leq 0.01 ; * * * p \leq 0.001$

${ }^{+}$The indices were categorized with a median split before determining the relationship of these variables with gender. 
Table 3. Correlations between respondents' educational experiences concerning leadership and perceptions of what constitutes leadership

\begin{tabular}{|c|c|c|c|}
\hline Indicators of Leadership & $\begin{array}{l}\text { Predoctoral } \\
\text { Education }^{+}\end{array}$ & $\begin{array}{c}\text { Experiences } \\
\text { After } \\
\text { Graduation: } \\
\text { Practice }\end{array}$ & $\begin{array}{c}\text { Experience } \\
\text { After } \\
\text { Graduation } \\
\text { Organizatio }\end{array}$ \\
\hline \multicolumn{4}{|l|}{ Recognition and effectiveness (Cronbach $\alpha=0.831$ ) } \\
\hline Being recognized by staff as an expert in the field of dentistry. & 0.05 & $0.19 * * *$ & $0.13^{* * *}$ \\
\hline Being recognized by patients as an expert in the field of dentistry. & $0.10^{*}$ & $0.21^{* * *}$ & $0.17^{* * *}$ \\
\hline Being recognized by other dentists as an expert in the field of dentistry. & $0.13^{* *}$ & $0.20^{* * *}$ & $0.25^{* * *}$ \\
\hline Being effective in managing staff. & $0.15^{* * *}$ & $0.21^{* * *}$ & $0.15^{* * *}$ \\
\hline Being effective in my community as an expert. & $0.15^{* * *}$ & $0.16^{* * *}$ & $0.18^{* * *}$ \\
\hline Index "Personal recognition" & $0.14^{* * *}$ & $0.25^{* * *}$ & $0.23^{* * *}$ \\
\hline \multicolumn{4}{|l|}{ Practice-related considerations (Cronbach $\alpha=0.846$ ) } \\
\hline Being the first dentist in an area to use new instruments or techniques. & $0.17^{* * *}$ & 0.06 & $0.15^{* * *}$ \\
\hline Owning a solo practice with associates. & 0.06 & -0.01 & 0.03 \\
\hline Owning a solo practice without associates. & $0.13 * *$ & 0.00 & 0.03 \\
\hline Being a partner in a group practice. & $0.13^{* *}$ & 0.02 & $0.09 *$ \\
\hline Index "Practice-related concerns" & $0.15^{* * *}$ & 0.02 & $0.10^{*}$ \\
\hline \multicolumn{4}{|l|}{ Organized dentistry (Cronbach $\alpha=0.900$ ) } \\
\hline Volunteering dental services in the community. & $0.22 * * *$ & $0.20^{* * *}$ & $0.24 * * *$ \\
\hline Being a leader in the community outside of dentistry. & $0.13^{* *}$ & $0.16^{* * *}$ & $0.26^{* * *}$ \\
\hline Holding local positions in organized dentistry. & $0.13^{* *}$ & $0.10^{*}$ & $0.20^{* * *}$ \\
\hline Organizing community events with a dental focus. & $0.14^{* *}$ & $0.10^{*}$ & $0.18^{* * *}$ \\
\hline Holding positions in organized dentistry in my state. & $0.13^{* *}$ & $0.08^{*}$ & $0.23 * * *$ \\
\hline Being involved in dentistry-related politics and the legislature. & $0.16^{* * *}$ & $0.09 *$ & $0.19 * * *$ \\
\hline Holding national positions in organized dentistry. & $0.13^{*}$ & 0.07 & $0.19^{*}$ \\
\hline Index "Organized dentistry" & $0.19 * * *$ & $0.14^{* *}$ & $0.27^{* * *}$ \\
\hline \multicolumn{4}{|l|}{ Research and teaching (Cronbach $\alpha=0.856$ ) } \\
\hline Teaching students about dentistry. & $0.10^{*}$ & $0.17^{* * *}$ & $0.20^{* * *}$ \\
\hline Teaching other dental professionals. & 0.06 & $0.12^{* *}$ & $0.17^{* * *}$ \\
\hline Publishing articles in dental journals. & $0.17^{*}$ & 0.06 & $0.11^{*}$ \\
\hline Being involved in research. & $0.15^{* * *}$ & 0.04 & $0.12^{* *}$ \\
\hline Index "Research and teaching" & $0.16^{* * *}$ & $0.12^{* *}$ & $0.18^{* * *}$ \\
\hline
\end{tabular}

Note: Response options for all indicators ranged from $1=$ disagree strongly to $5=$ agree strongly that this statement indicates leadership.

${ }^{*} \mathrm{p} \leq 0.05 ;{ }^{* *} \mathrm{p} \leq 0.01 ;{ }^{* * *} \mathrm{p} \leq 0.001$

${ }^{+}$Responses were given on a five-point scale, with $5=$ best level of educational experiences.

evaluated practice-related aspects of their lives as indicative of leadership.

Concerning the second factor of interest in Aim 3 (leadership-related values/attitudes), the perceived quality of the respondents' leadership training in predoctoral education and after graduation was related to their overall importance ratings (Table 4). However, the perceived quality of their leadershiprelated predoctoral education did not significantly correlate with responses to the two single items concerning how important it was to them to be a good leader in their practice and being seen by their patients as a good leader.

The third factor of interest under Aim 3 was the dentists' evaluations of their effectiveness as leaders in their own practices and in their profession. While the perceived quality of the respondents' leadershiprelated predoctoral education was not correlated with how effective they saw themselves as leaders in their own practice, it was correlated with their perceived effectiveness as leaders in their profession (Table 4). However, both the respondents' practice-related and organization-related education after graduation correlated with the two effectiveness responses.

The final construct of interest in relationship to the quality of educational experiences was the respondents' actual leadership-related activities/behavior in the past as well as at the present time. The numbers of dental hygienists and dental assistants in a practice were seen as one indicator of leadership- 
Table 4. Correlations between respondents' educational experiences and their values/attitudes about aspects of leadership and self-perceived effectiveness as a leader

\begin{tabular}{|c|c|c|c|}
\hline Value/Attitude & $\begin{array}{c}\text { Predoctoral } \\
\text { Education }^{+}\end{array}$ & $\begin{array}{c}\text { Experiences } \\
\text { After } \\
\text { Graduation: } \\
\text { Practice }\end{array}$ & $\begin{array}{c}\text { Experiences } \\
\text { After } \\
\text { Graduation: } \\
\text { Organization }\end{array}$ \\
\hline \multicolumn{4}{|l|}{ How important is it for you that: (Cronbach $\alpha=0.817$ ) } \\
\hline you are a good leader in your practice. & 0.02 & $0.23 *$ & $0.15^{*}$ \\
\hline my patients think of me as a leader. & 0.06 & $0.22 *$ & $0.21 *$ \\
\hline you are a good leader in your profession. & $0.22 *$ & $0.21^{*}$ & $0.34 *$ \\
\hline dentists take a greater leadership role. & $0.18^{*}$ & $0.15^{*}$ & $0.33^{*}$ \\
\hline there are at least as many leaders in dentistry as in other professions. & $0.19^{*}$ & $0.16^{*}$ & $0.22 *$ \\
\hline my peers think of me as a leader. & $0.25^{*}$ & $0.18^{*}$ & $0.36^{*}$ \\
\hline Index "Importance" & $0.23 *$ & $0.26^{*}$ & $0.39 *$ \\
\hline \multicolumn{4}{|l|}{ How effective are you as a leader: } \\
\hline in your own practice. & 0.07 & $0.26^{*}$ & $0.22 *$ \\
\hline in your profession. & $0.24^{*}$ & $0.17^{*}$ & $0.41 *$ \\
\hline
\end{tabular}

related behavior in addition to the number of past and current leadership activities reported in response to two open-ended questions. While there was a small but significant correlation between the respondents' perceived quality of their leadership-related predoctoral education and the number of dental hygienists in their practices, no other significant relationships were found between this type of education and these outcome variables (Table 5). The practice-related educational experiences after graduation were correlated with the numbers of dental hygienists and dental assistants as well as with the numbers of reported past and current leadership experiences in organizations and in the profession in general. The organizational leadership-related educational experiences after graduation correlated positively with the number of dental hygienists and dental assistants in the respondents' practices and with their current practice-related leadership indicators. They were also correlated with the index of past practicerelated experiences.

\section{Discussion}

The data analyzed in this study were collected from a diverse group of respondents who ranged in age from twenty-seven to ninety-seven years and had received their dental degrees from fifty-four U.S. dental schools and sixteen dental schools outside the United States. The fact that the majority of the responding dentists were male and from European American backgrounds shows that the sample reflects the characteristics of most practicing general dentists in the United States.

The findings concerning leadership-related predoctoral educational experiences support the results of previous studies ${ }^{6,8}$ that found limited leadership-related educational efforts in predoctoral dental programs. In our study, the respondents on average disagreed or were neutral when asked to indicate how much they agreed that their predoctoral education had prepared them well for leadership tasks. Only a limited number of U.S. dental schools have so far invested in developing specific leadership programs in their predoctoral programs. ${ }^{28}$ In 2006, the University of Michigan School of Dentistry introduced an extracurricular program called the Scholars Program in Dental Leadership (SPDL), which focuses on leadership development through guest lectures and focused student projects. ${ }^{6}$ Since 2010, elements of the SPDL have been incorporated into the predoctoral "Pathways" curriculum. ${ }^{29}$ The University of Southern California Ostrow School of Dentistry has a leadership program predominantly focused on graduate student and faculty development, with some predoctoral students participating. ${ }^{30}$ Similarly, the Harvard School of Dental Medicine launched a course on leadership for its postdoctoral dental students in 2010, designed to introduce the lat- 


\begin{tabular}{|c|c|c|c|}
\hline Practice Characteristics/Leadership Activities & $\begin{array}{l}\text { Predoctoral } \\
\text { Education }^{+}\end{array}$ & $\begin{array}{l}\text { Experiences } \\
\text { After } \\
\text { Graduation: } \\
\text { Practice }\end{array}$ & $\begin{array}{c}\text { Experiences } \\
\text { After } \\
\text { Graduation: } \\
\text { Organization }\end{array}$ \\
\hline \multicolumn{4}{|l|}{ Practice characteristics } \\
\hline Number of dental hygienists in practice & $0.09 *$ & $0.14^{* * *}$ & $0.13^{* * *}$ \\
\hline Number of dental assistants in practice & 0.06 & $0.10^{*}$ & $0.10^{*}$ \\
\hline \multicolumn{4}{|l|}{ Number of past leadership activities } \\
\hline in own practice & 0.04 & -0.02 & $-0.09 *$ \\
\hline in community & 0.03 & 0.06 & $0.08^{*}$ \\
\hline in organization and the profession in general & 0.02 & $0.08^{*}$ & $0.15^{* *}$ \\
\hline Total & -0.01 & 0.08 & $0.10^{*}$ \\
\hline \multicolumn{4}{|l|}{ Number of current leadership activities } \\
\hline in own practice & 0.04 & 0.04 & 0.03 \\
\hline in community & 0.02 & 0.05 & 0.05 \\
\hline in organization and the profession in general & 0.01 & $0.09 *$ & $0.15^{* * *}$ \\
\hline Total & 0.01 & $0.11^{* *}$ & $0.13^{* * *}$ \\
\hline \multicolumn{4}{|c|}{${ }^{+}$Responses were given on a five-point scale, with $5=$ best level of educational experiences. } \\
\hline \multicolumn{4}{|l|}{${ }^{*} \mathrm{p} \leq 0.05 ; * * \mathrm{p} \leq 0.01 ; * * * \mathrm{p} \leq 0.001$} \\
\hline
\end{tabular}

est leadership theories and principles through the use of case studies, role-play, and self-reflection. ${ }^{26}$ The University of the Pacific Arthur A. Dugoni School of Dentistry emphasizes leadership training as one of its core values and offers a series of retreats, programs, and seminars on leadership development. ${ }^{13}$ At the Case Western Reserve University School of Dental Medicine, a program aims to increase dental students' knowledge and leadership skills and provide exposure to leaders who can serve as role models for graduates. ${ }^{7}$ A program aimed at educating dental students about taking a leadership role on a statewide level is offered at Indiana University. ${ }^{14}$ One positive finding of our study related to the quality of predoctoral experiences can be seen in the fact that the more recently these respondents had graduated, the more positive they evaluated their predoctoral education to be (see Table 2).

In comparison to the mediocre evaluations of the respondents' predoctoral education related to leadership, their responses concerning the quality of their educational experiences after dental school were significantly more positive. However, the absence of correlations found between the respondents' graduation years and the quality of the educational experiences after dental school leads to the question of how these experiences can be improved in the future. For example, it could be worthwhile to explore ways in which dental schools could contribute to shaping these educational experiences through continuing education programs. In addition, professional organizations could potentially play an important role in this context.

Concerning the educational experiences of male versus female dentists, previous research found no differences between male and female students' and residents' experiences. ${ }^{10,20}$ However, the findings in our study showed that the female practitioners evaluated their leadership-related dental school experiences more positively than their male colleagues did. In addition, the female practitioners described their leadership-related experiences related to interactions and consultations with colleagues in other practices and organizational leadership activities more positively than did their male colleagues. Future research should focus on gaining a better understanding of these gender-related findings and their implications.

The fact that educational experiences are important for leadership-related professional considerations and values/attitudes is demonstrated in the findings reported in Tables 3 and 4 . The better the respondents rated the quality of their leadershiprelated predoctoral education and education after graduation, the more they considered various aspects of their professional lives in general as well as their professional activities in their communities and at 
state and national levels as indicators of leadership. This may suggest that positive predoctoral educational experiences can increase graduates' understanding of the degree to which the various aspects of dentists' professional lives are related to leadership activities. These findings should again alert dental educators to develop solid educational programs for both predoctoral students and practicing dentists. In addition, it is noteworthy to consider that the quality of leadership-related educational experiences was significantly correlated to the respondents' considerations of the degree to which research and teaching were relevant activities. Given the faculty shortage in dental education, ${ }^{31}$ it might be interesting to explore whether leadership-related training could motivate dentists to consider at least part-time if not full-time academic careers.

Our study findings that both predoctoral education and education after graduation were significantly related to the respondents' attitudes is not surprising given other research that reported dental education can shape attitudes towards practice patterns. ${ }^{32-36}$ However, while those studies found relationships between educational experiences and professional behavior, no significant correlations between predoctoral education and practice characteristics and past and current leadership experiences were found in our study. One could argue that a minimal level of education might have to be reached before it translates into professional behavior. This consideration would be supported by the findings that there were significant correlations between the number of past and current leadership-related experiences and educational experiences after dental school because on average these later experiences had been more positive than the earlier predoctoral experience.

This study had limitations, beginning with its low response rate, despite the use of postal mail for collecting the data. Hardigan et al. found that 94 percent of dentists preferred responding to a survey via postal mail versus online. ${ }^{37}$ They also found that the response rates for mailed surveys were on average 28 percent - which is higher than the 20 percent response rate to our survey. One might argue that this relatively lower response rate suggests that ADA members and U.S. dentists in general do not value leadership-related research highly and thus were not motivated to respond to this mailing. However, the fact that the responses came from dentists in all age groups, from 90 percent of U.S. states, and from the majority of U.S. dental schools shows that this sample was diverse and thus provided a good basis from which to explore these issues. A second limitation is the fact that this study focused on dentists' own perceptions and responses regarding their leadership-related educational experiences, attitudes, and behavior. Our objective was not to obtain an objective assessment of dentists' actual leadership skills and behavior; however, future research should go beyond exploring self-perceptions to evaluating dentists' leadership behavior/skills in a more objective fashion by using feedback from superiors, colleagues, and/or subordinates.

\section{Conclusion}

The findings of this study suggest that leadership-related predoctoral education may need to be improved and to be introduced in more U.S. dental schools. The fact that the more recently dentists had graduated from dental schools, the more positively they described these experiences may indicate that leadership training is being expanded and is beginning to have an effect. Furthermore, dental educators and professional organizations should explore how to increase leadership-related educational opportunities for practicing dentists.

\section{Acknowledgments}

We thank the American Dental Association for providing us with its members' addresses and Alexandra Forest for collaborating on designing this study. We also want to thank Michael Hyman, Yash Murthy, Charles Wenzel, and Benjamin Yoon for help with mailing the surveys and preparation of the data for analysis. This project was supported by the Major M. Ash Collegiate Professorship, Department of Periodontics and Oral Medicine, University of Michigan School of Dentistry.

\section{REFERENCES}

1. Formicola AJ, Andrieu SC, Buchanan JA, et al. Interprofessional education in U.S. and Canadian dental schools: an ADEA team study group report. J Dent Educ 2012;76(9):1250-68.

2. Brown LJ. Introduction and guide to the special issue on economic and workforce issues facing dentistry and dental education in the twenty-first century. J Dent Educ 2012;76(8):965-72.

3. Roth K. Dental education: a leadership challenge for dental educators and practitioners. J Dent Educ 2007;71(8): 983-7.

4. Morison S, McMullan C. Preparing for the future: challenges and opportunities for management and leadership skills. Br Dent J 2013;214(1):E2. 
5. Steinert Y, Naismith L, Mann K. Faculty development initiatives designed to promote leadership in medical education: a BEME systematic review. BEME Guide No. 19. Med Teach 2012;34(6):483-503.

6. Taichman RS, Green TG, Polverini PJ. Creation of a scholars program in dental leadership (SPDL) for dental and dental hygiene students. J Dent Educ 2009;73(10): 1139-43.

7. Victoroff KZ, Schneider K, Perry C. Leadership development for dental students: what do students think? J Dent Educ 2008;72(9):982-8.

8. Kalenderian E, Skoulas A, Timothe P, Friedland B. Integrating leadership into a practice management curriculum for dental students. J Dent Educ 2010;74(5):464-71.

9. Weaver RG, Chmar JE, Haden NK, Valachovic RW. Annual ADEA survey of dental school seniors, 2004 graduating class. J Dent Educ 2005;69(5):595-619.

10. Chmar JE, Harlow AH, Weaver RG, Valachovic RW. Annual ADEA survey of dental school seniors, 2006 graduating class. J Dent Educ 2007;71(9):1228-53.

11. Okwuje I, Anderson E, Valachovic RW. Annual ADEA survey of dental school seniors, 2008 graduating class. J Dent Educ 2009;73(8):1009-32.

12. Barber M, Wiesen R, Arnold S, et al. Perceptions of business skill development by graduates of the University of Michigan Dental School. J Dent Educ 2011;75(4):505-17.

13. Hammer DA, Nadershahi NA. Assessing the demand and preferred format of a student leadership development program at Pacific. J Dent Educ 2011;75(8):1044-52.

14. Yoder KM, Edelstein BL. Oral health policy forum: developing dental student knowledge and skills for health policy advocacy. J Dent Educ 2012;76(12):1572-9.

15. Sinkford JC. Introduction to the Fourth ADEA International Women's Leadership Conference Proceedings. J Dent Educ 2011;75(3 Suppl):S5-7.

16. Woolfolk MW, Price SS. Dental education: evolving student trends. J Dent Educ 2012;76(1):51-64.

17. Atchison KA, Thind A, Carreon DC, et al. Comparison of extramural clinical rotation days: did the pipeline program make a difference? J Dent Educ 2012;75(1):52-61.

18. del Aguila MA, Leggott PJ, Robertson PB, et al. Practice patterns among male and female general dentists in a Washington State population. J Am Dent Assoc 2005; 136(6):790-6.

19. Rafeek RN, Marchan SM, Naidu RS, Carrotte PV. Perceived competence at graduation among dental alumni of the University of the West Indies. J Dent Educ 2004;68(1):81-8.

20. Andersen RM, Davidson PL, Atchison KA, et al. Pipeline, profession, and practice program: evaluating change in dental education. J Dent Educ 2005;69(2):239-48.

21. Donoff RB, Ritrievi KE. Educating future leaders of the oral health community. Compend Contin Educ Dent 2011; 32(5):88
22. Greenspan JS. Global health and dental education: a tipping point? J Dent Educ 2013;77(10):1243.

23. Ivanoff CS, Ivanoff AE, Yaneva K, et al. Student perceptions about the mission of dental schools to advance global dentistry and philanthropy. J Dent Educ 2013;77(10):1258-69.

24. Seymour B, Benzian HH, Kalenderian E. Volunteerism and global health: preparing dental students for responsible engagement in international programs. J Dent Educ 2013;77(10):1252-7.

25. Seymour B, Barrow J, Kalenderian E. Results from a new global oral health course: a case study at one dental school. J Dent Educ 2013;77(10):1245-51.

26. Skoulas A, Kalenderian E. Leadership training for postdoctoral dental students. J Dent Educ 2012;76(9):1156-66.

27. Goldstein AO, Calleson D, Bearman R, et al. Teaching advanced leadership skills in community service (ALSCS) to medical students. Acad Med 2009;84(6):754-64.

28. Kalenderian E, Taichman RS, Skoulas A, et al. Developing the next generation of leaders in oral health. J Dent Educ 2013;77(11):1506-12.

29. Taichman RS, Parkinson JW, Nelson BA, et al. Leadership training for oral health professionals: a call to action. J Dent Educ 2010;76(2):185-91.

30. Slavkin HC, Lawrence L. Incorporating leadership knowledge and skills into the dental education community. J Dent Educ 2007;71(6):708-12.

31. Livingston HM, Dellinger TM, Hyde JC, Holder R. The aging and diminishing dental faculty. J Dent Educ 2004;68(3):345-54.

32. Dao LP, Zwetchkenbaum S, Inglehart MR. General dentists and special needs patients: does dental education matter? J Dent Educ 2005;69(10):1107-15.

33. Smith CS, Ester TV, Inglehart MR. Dental education and care for underserved patients: an analysis of students' intentions and alumni behavior. J Dent Educ 2006;70(4):398-408.

34. Weil TN, Inglehart MR. General and pediatric dentists' professional attitudes and behavior concerning patients with autism: does dental education matter? J Dent Educ 2010;74(12):1294-307.

35. Brown BR, Inglehart MR. Orthodontists' and orthodontic residents' education about treating underserved patients: effects on professional attitudes and behavior. J Dent Educ 2009;73(5):550-62.

36. Garfinkle AJ, Richards PS, Inglehart MR. Providing care for underserved patients: periodontists' and periodontal residents' educational experiences, attitudes, and behavior. J Periodontol 2010;81(11):1-9.

37. Hardigan PC, Succar CT, Fleisher JM. An analysis of response rate and economic costs between mail and webbased surveys among practicing dentists: a randomized trial. J Community Health 2012;37(2):383-94. 